IRA-International Journal of Management \& Social Sciences

ISSN 2455-2267; Vol.03, Issue 03 (2016)

Institute of Research Advances

http://research-advances.org/index.php/RAJMSS

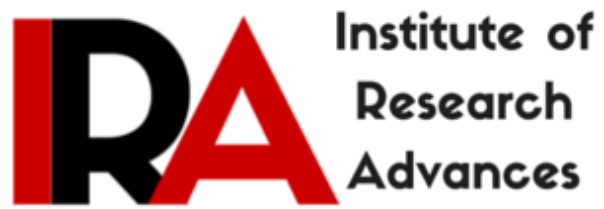

\title{
Emotional Intelligence and Stress Coping Styles: A Study of Doctors of Private Hospitals in and Around Chandigarh
}

\author{
${ }^{1}$ Ms. Ritu Sharma \\ Assistant Professor, \\ University School of Business, \\ Chandigarh University, Gharuan, India. \\ ${ }^{2}$ Mr. Parmod Kumar \\ Assistant Professor, \\ University School of Business, \\ Chandigarh University, Gharuan, India.
}

DOI: http://dx.doi.org/10.21013/jmss.v3.n3.p24

How to cite this paper:

Sharma, R., \& Kumar, P. (2016). Emotional Intelligence and Stress Coping Styles: A Study of Doctors of Private Hospitals in and Around Chandigarh. IRA-International Journal of Management \& Social Sciences (ISSN 2455-2267), 3(3). doi:http://dx.doi.org/10.21013/jmss.v3.n3.p24

(C) Institute of Research Advances

(cc) $\mathrm{EY}$-NC

This works is licensed under a Creative Commons Attribution-Non Commercial 4.0 International License subject to proper citation to the publication source of the work.

Disclaimer: The scholarly papers as reviewed and published by the Institute of Research Advances (IRA) are the views and opinions of their respective authors and are not the views or opinions of the IRA. The IRA disclaims of any harm or loss caused due to the published content to any party. 


\section{ABSTRACT}

Emotional Intelligence, or EI, describes an ability or capacity to perceive, assess, and manage the emotions of one's self, and of others. Goleman describes emotional intelligence as "managing feelings so that they are expressed appropriately and effectively, enabling people to work together smoothly toward their common goals." According to Goleman, the four major skills that make up emotional intelligence are: Self-Awareness, Self-Management, Social Awareness and Relationship Management. Stress is a fact of life and is inevitable in this competitive world. From individual point of view stress is our body's physical, chemical and mental reaction to circumstances that frighten, confuse, endanger or irritate us. It can lead to physiological discomfort, some kind of emotional unhappiness, and even strained relationship with others. EI has been linked with various stress coping strategies particularly rational/problem focused coping. The link between EI and stress is also established in the academic literature. Stress Coping strategies refer to the specific efforts, both behavioral and psychological, that people employ to master, tolerate, reduce, or minimize stressful events. Proposed study is an attempt to find out the relationship between emotional intelligence and stress coping styles among doctors of private hospitals in and around Chandigarh.

Keywords: Emotional Intelligence, Stress

\section{Introduction}

Emotional Intelligence, or EI, means an ability or capacity to perceive, assess, and manage the emotions of one's self, and of others. Goleman describes emotional intelligence as "managing feelings so that they are expressed appropriately and effectively, enabling people to work together smoothly toward their common goals." According to Goleman, emotional intelligence consists of four skills: Self-Awareness, Self-Management, Social Awareness and Relationship Management. Stress is a fact of life and is inevitable in this competitive world. From individual point of view, stress is our body's physical, chemical and mental reaction to circumstances that frighten, confuse, endanger or irritate us. It can lead to physiological discomfort, some kind of emotional unhappiness, and even strained relationship with others. EI has been linked with various stress coping strategies particularly rational/problem focused coping. The link between EI and stress is also established in the academic literature. Stress Coping strategies refer to the specific efforts, both behavioral and psychological, that people employ to master, tolerate, reduce, or minimize stressful events. There are three major stress coping styles: the problem focused coping style that emphasizes on reducing pressure or increasing stress management skills; avoidant-focused coping style focusing on confronting stress factor; and emotional-focused coping which includes cognitive strategies that delay solving or removing stress factor by giving a new name and meaning. New classification of four coping styles include logical, detached, emotional and avoidant styles. Logical coping is like problem-focused strategy and detached coping is an approach based the individual's tendency to get far away from the problem to face it and reduce the potential influence of emotions. Logical and detached coping is generally regarded as efficient styles and emotional and avoidant style as inefficient styles

High emotional intelligence levels are associated with coping strategies based on reflection and problem solving, while low levels are associated with coping strategies based on avoidance, rumination and superstition. Therefore, emotional intelligence plays 
an important role in the emotional self-control and the individual's adaptive capacity to cope with stressful situations.

\section{Models of Emotional Intelligence}

Below is a brief summary of the three main models of emotional intelligence and how they differ.

\section{- Salovey/Mayer/Caruso}

In their mental ability model, they define emotional intelligence as "the ability to perceive accurately, appraise, and express emotion; the ability to access and/or generate feelings with thought; the ability to understand emotion and emotional knowledge; and the ability to regulate emotions to promote emotional and intellectual growth." Salovey, Mayer and Caruso have attempted to keep their definition research based to enable them to continue to refine their study in this field.

The Mayer/Salovey/Caruso ability model of emotional intelligence looks at two areas of Emotional Intelligence:

1. Experiential Emotional Intelligence (EEIQ) - which includes the ability to perceive, respond, and manipulate emotional information without necessarily understanding it.

2. Strategic Emotional Intelligence (SEIQ) - which includes the ability to understand and manage emotions without necessarily perceiving feelings well or fully experiencing them.

These two core areas of emotional intelligence are then broken into the "four branch model" (as it is often called). These include:

(i) Perceiving Emotion - is the ability to identify and express emotions and emotional needs accurately to others. It is the ability to decode emotional signals in facial expressions, tone of voice and artistic expression. This is considered an experiential component of emotional intelligence, as it is about a person's basic ability to process or "experience" emotional information.

(ii) Facilitating Thought - is the ability to use emotion to facilitate thinking, problem solving, reasoning and focus. This is about blending emotion and thinking while being aware of how emotion might be affecting your thoughts. This is also considered an experiential component of emotional intelligence.

(iii)Understanding Emotion - is defining complex emotional blends and understanding emotional transitions. This is the ability to understand how emotions might combine, change and manifest over time. This is considered a strategic component of emotional intelligence.

(iv) Managing Emotions - is the ability to manage emotions appropriately and successfully. It is the ability to be open to emotional information when important, and closed to it when it is not, then effectively include emotion into thought. This is considered a strategic component of emotional intelligence.

\section{- Bar-On}

The Bar-On model is considered a "mixed model" of emotional intelligence and is quite well known.

"According to the Bar-On model, emotional-social intelligence is a cross-section of interrelated emotional and social competencies, skills and facilitators that determine how well we understand and express ourselves, understand others and relate with them, and cope with daily demands, challenges and pressures. The emotional and 
social competencies, skills and facilitators included in this broad definition of the construct are based on the 5 meta-factors defined below, that were confirmed by a series of second order factor analyses in the development of the Bar-On psychometric measure of this construct."

This Bar-On model looks at five core factors and fifteen sub components:

1. Intrapersonal - relates to self-awareness and self-expression, governing our ability to be aware of our emotions and ourselves in general, to understand our strengths and weaknesses, and to express our feelings and ourselves nondestructively. It consists of sub factors including self-regard, emotional selfawareness, assertiveness, independence and self-actualization.

2. Interpersonal - relates to our ability to be aware of others' feelings, concerns and needs, and to be able to establish and maintain cooperative, constructive and mutually satisfying relationships. It consists of sub factors including empathy, social responsibility and interpersonal relationships.

3. Stress Management - relates to emotional management and controlling our ability to deal with emotions so that they work for us and not against us. It consists of sub factors including stress, tolerance, and impulse control.

4. Adaptability - relates primarily to change management i.e., how we cope with and adapt to personal and interpersonal change as well as change in our immediate environment. It consists of sub factors including reality testing, flexibility, and problem solving.

5. General Mood - relates to our level of self-motivation. It consists of sub factors including optimism and happiness.

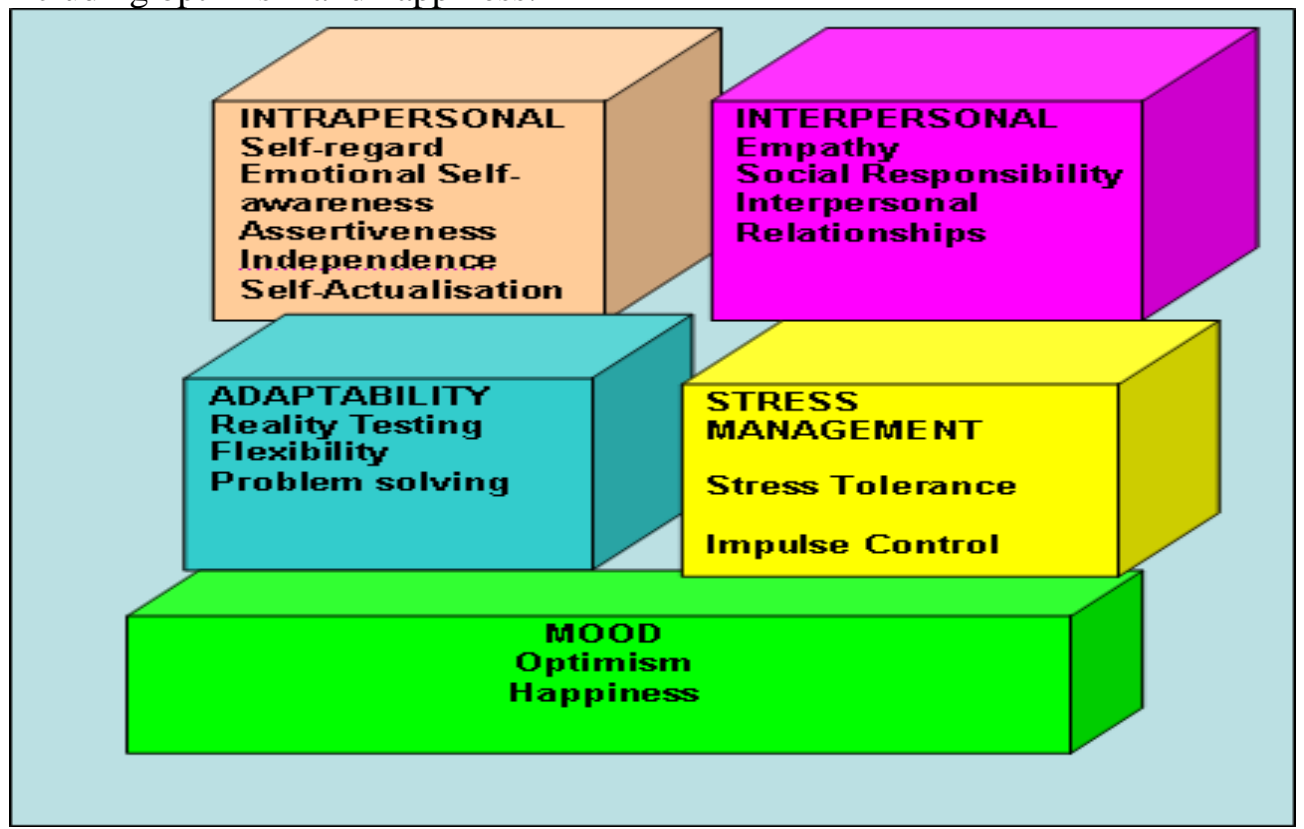

- Goleman Model

Goleman popularized this concept with the publication of his influential book Emotional Intelligence in 1995 that appeared on the cover page of TIME magazine. Goleman's later writings in the field of social and emotional intelligence have seen him rename the five original competencies, and combine them into four:

1. Self-Awareness - emotional self-awareness, accurate self-assessment, selfconfidence.

2. Social Awareness - empathy, organizational awareness, service orientation. 
3.Self-Management - self-control, trustworthiness, conscientiousness, adaptability, achievement orientation, initiative.

4. Social Skills - developing others, leadership, influence, communication, change catalyst, conflict management, building bonds, teamwork.

We have chosen to utilise the Goleman "mixed model" as the basis for our TTI emotional quotient. The Goleman model is relatively simple, yet powerful. It is easily applied in both a personal and professional setting, and tends to be more widely used and accepted in an organizational setting. At the same time, we must recognize, respect, and include the thoughts, contributions and commitment of other researchers and contributors in the field.

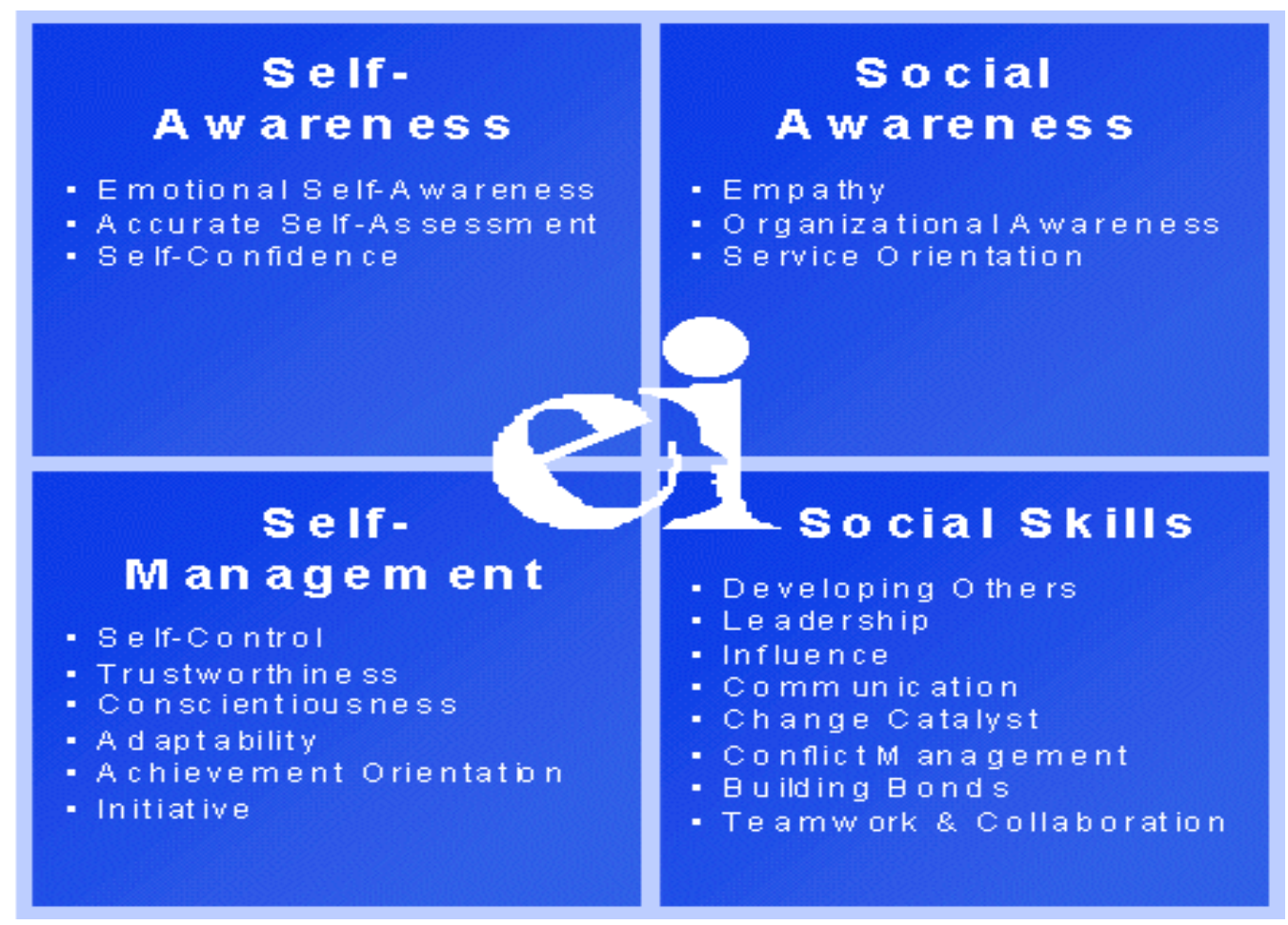

\section{Need and Purpose of the study}

This present study aims at exploring the relation between emotional intelligence and stress coping style among doctors of private hospital in and around Chandigarh. Emotional intelligence is an important trait for handling stress at work place. It is hypothesized that there will be significant influence of emotional intelligence on stress level among doctors in private hospitals. Emotional intelligence is assuming unprecedented importance due to growing concern of people management in the hospitals.

\section{Scope of the Study}

The study is limited to the doctors of private hospitals in and around Chandigarh. 120 doctors from two private hospitals-Fortis Healthcare Ltd and Mukat Hospital and Health Institute were randomly selected for this study. 


\section{Objectives}

1. To study the emotional intelligence and stress coping style of the doctors of the private hospitals.

2. To find out the relationship between emotional intelligence and stress coping style of the doctors of the private hospitals.

3. To see the associations between emotional intelligence and stress coping style of the doctors of the private hospitals with demographic variables.

4. To find out the impact of emotional intelligence on stress level of doctors of the private hospitals.

5. To suggest and make recommendation for enhancing emotional intelligence.

\section{Hypothesis}

A hypothesis is a tentative statement about the relationship between two or more variables. A hypothesis is a specific, testable prediction about what you expect to happen in your study. The hypotheses for my studies are as follows:-

H1a.Doctors of few selected hospitals has high level of Emotional Intelligence.

H1b. Doctors of few selected hospitals have high level of Stress Coping Styles.

$\mathrm{H} 2$. There is a positive and significant relationship emotional intelligence and stress coping styles.

$\mathrm{H} 3 \mathrm{a}$. There is a positive and significant relationship between gender and stress coping styles.

H3b. There is a positive and significant relationship between marital status and stress coping styles.

$\mathrm{H} 3 \mathrm{c}$. There is a positive and significant relationship between experience and stress coping styles.

\section{Data Collection Tool}

Standardized questionnaire

\section{Analysis and Interpretation}

Analysis is done using Statistical Software (SPSS). Data interpretation is the study of scientific measurements and observations to develop evidence for responding to a query. The common tools used for data interpretation are electronic spreadsheets which are capable of sorting, graphing and searching data. In this study, following statistical tools have been used:

\section{- Correlation}

- Analysis Of Variance (ANOVA)

- Independent t-test

The present study focuses at studying emotional intelligence and its relation with stress coping styles in the private hospitals in and around Chandigarh. The doctors are mapped on these variables through questionnaire and standardized scale. To study the emotional 
intelligence of the doctors a questionnaire framed by Wong and Law is used and stress coping styles are studied through Carver, Scheier and Weintraub model. Scoring is done through scoring keys and according to the norms in the manual. The scores are analyzed using statistical techniques viz. Means, Standard Deviations, Independent t-test, Analysis of Variance (ANOVA) and Pearson's Correlation.

\section{Reliability Test}

All variables have been taken for checking the reliability of data. Total number of data (N) is 101.

\section{Reliability Statistics}

Table 4.1

\begin{tabular}{|c|c|}
\hline & \\
Cronbach's Alpha & N of Items \\
\hline .826 & 44 \\
\hline
\end{tabular}

The test for reliability has been conducted with the responses of emotional intelligence and stress coping style $(\alpha=0.826)$ and it is found that the Cronbach's alpha is above 0.7. Hence the scale can be considered reliable with the sample.

\section{Normality Test}

Table 4.2: Tests of Normality

\begin{tabular}{|l|l|l|l|l|l|l|}
\hline \multirow{4}{*}{} & \multicolumn{3}{|l|}{ Kolmogorov-Smirnov ${ }^{\text {a }}$} & \multicolumn{2}{l|}{ Shapiro-Wilk } \\
\cline { 2 - 7 } & Statistic & Df & Sig. & Statistic & df & Sig. \\
\hline SCS & .077 & 101 & .153 & .979 & 101 & .099 \\
EI & .124 & 101 & .001 & .906 & 101 & .061 \\
\hline
\end{tabular}

a. Lilliefors Significance Correction

SCS $=$ Stress Coping Styles

$\mathrm{EI}=$ Emotional Intelligence

Conducting the tests of normality on the data of emotional intelligence and stress coping style support, the results obtained are Emotional Intelligence: $\mathrm{D}(101)=0.061$, Stress Coping Style: $\mathrm{D}(101)=0.099$. 
Thus we can conclude that the data of emotional intelligence and stress coping style is normal. This is also verified by analyzing the Skewness, Kurtosis values and is clearly visible in the histogram and the Q-Q plot.

\section{HYPOTHESIS TESTING:}

In order to achieve the objective, hypothesis is formulated. Statistical measures like mean, standard deviation, descriptive, correlation, and ANOVA, are applied to the data collected from the doctors of few selected hospitals through questionnaire.

H1a.Doctors of few selected hospitals have high level of Emotional Intelligence.

H1b. Doctors of few selected hospitals have high level of Stress Coping Styles.

\section{Descriptive Statistics}

Table 4.3.1

\begin{tabular}{|c|c|c|c|}
\hline & Mean & Std. Deviation & $\mathrm{N}$ \\
\hline EI & 50.0421 & 7.25420 & 101 \\
SCS & 77.1208 & 11.87271 & 101 \\
\hline
\end{tabular}

SCS $=$ Stress Coping Styles

$\mathrm{EI}=$ Emotional Intelligence

We have got information from 101 respondents $(\mathrm{N}=101)$, and based on the descriptive statistics, as in the above table, for emotional intelligence, the calculated mean is 50.0421and for stress coping style, the calculated mean is 77.1208 , which is above average on a scale of 1 to 5. Therefore, it is concluded that samples taken have high level of Emotional intelligence and Stress Coping Styles.

From the above result, it can be concluded that the hypothesis H1a and hypothesis H1b are accepted. The level of emotional intelligence and stress coping styles is moderately high among doctors of private hospitals.

\section{H2. There is a positive and significant relationship emotional intelligence and stress coping styles.}

\section{Correlations}

Table 4.3.2

\begin{tabular}{|ll|l|l|}
\hline & EI & SCS \\
\hline EI & Pearson Correlation & 1 & $.204^{*}$ \\
& Sig. (2-tailed) & & .040 \\
& $\mathrm{~N}$ & 101 & 101 \\
\hline SCS & Pearson Correlation & $.204^{*}$ & 1 \\
& Sig. (2-tailed) & .040 & \\
& $\mathrm{~N}$ & 101 & 101 \\
\hline
\end{tabular}

*. Correlation is significant at the 0.05 level (2-tailed). 
SCS $=$ Stress Coping Styles

$\mathrm{EI}=$ Emotional Intelligence

From the above table it is concluded that there is a positive relation between emotional intelligence and stress coping style. The Sig. Value is .204 that is more than $\alpha=0.05$. They are not highly correlated but they are moderately correlated with each other. Hence it is proved that doctor's high on emotional intelligence would be more effective to manage the stress.

From the above result, it can be concluded that the hypothesis $\mathbf{H} 2$ is accepted.

H3a. There is a positive and significant relationship between gender and stress coping styles.

\section{T-Test}

Group Statistics

Table 4.3.3

\begin{tabular}{|c|c|c|c|c|c|}
\hline & Gender & $\mathrm{N}$ & Mean & Std. Deviation & Std. Error Mean \\
\hline \multirow[t]{2}{*}{ SCS } & Male & 46 & 81.3184 & 12.88567 & 1.89989 \\
\hline & Female & 55 & 73.6101 & 9.75239 & 1.31501 \\
\hline
\end{tabular}

Independent Samples Test

Table 4.3.3.1

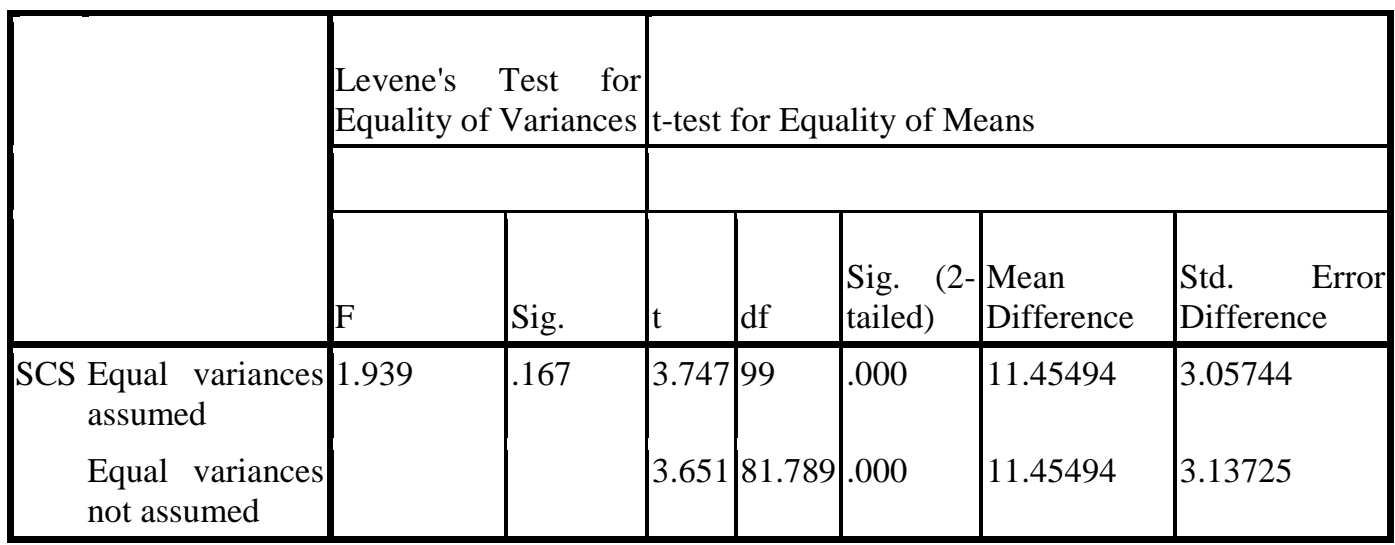

SCS $=$ Stress Coping Styles

An independent-sample t-test was conduct to compare the stress coping styles for male and females. There was no significant difference in score of males $(\mathrm{M}=81.3184, \mathrm{SD}=$ 12.88567) and females $[\mathrm{M}=73.6101, \mathrm{SD}=9.75239 ; \mathrm{t}(99)=.100]$. The magnitude of the difference in the mean value is not very large.

From above it is proved that there is positive and significant relationship between gender and stress coping style.

From the above result, it can be concluded that the hypothesis H3a is accepted. 
H3b. There is a positive and significant relationship between marital status and stress coping styles.

\section{One-way}

Test of Homogeneity of Variances

Table 4.3.3.2

SCS

\begin{tabular}{|l|l|l|l|}
\hline & & & \\
Levene Statistic & df1 & df2 & Sig. \\
\hline 2.242 & 2 & 98 & .112 \\
\hline
\end{tabular}

ANOVA

Table 4.3.3.3

SCS

\begin{tabular}{|l|l|l|l|l|l|}
\hline & Sum of Squares & Df & Mean Square & F & Sig. \\
\hline Between Groups & 741.601 & 2 & 370.801 & 2.721 & .071 \\
Within Groups & 13354.513 & 98 & 136.271 & & \\
Total & 14096.114 & 100 & & & \\
\hline
\end{tabular}

Multiple Comparisons

Table 4.3.3.4

SCS
\begin{tabular}{|ll|l|l|l|}
\hline \multicolumn{1}{|l|}{} & \multicolumn{2}{c|}{$\begin{array}{l}\text { Mean Difference } \\
\text { (I-J) }\end{array}$} & Std. Error & \multicolumn{1}{c|}{ Sig. } \\
\hline Married & Unmarried & -.73784 & 2.47685 & .952 \\
& Single & -10.86446 & 4.67084 & .057 \\
\hline
\end{tabular}




\begin{tabular}{|ll|l|l|l|}
\hline Unmarried & Married & .73784 & 2.47685 & .952 \\
& Single & -10.12662 & 4.82209 & .095 \\
\hline Single & Married & 10.86446 & 4.67084 & .057 \\
& Unmarried & 10.12662 & 4.82209 & .095 \\
\hline
\end{tabular}

SCS $=$ Stress Coping Styles

A one way between groups is conducted to explore the impact of marital status on stress coping style, as measured by life orientation test (LOT). Subjects are divided into three groups (group1 - married, group 2 - unmarried, group 3 - single). Here the significant value .071 it is greater than .05 .

There is a no positive and significant relationship between marital status and stress coping styles.

From the above result, it can be concluded that the hypothesis H3b is not accepted.

H3c. There is a positive and significant relationship between experience and stress coping styles

\section{One-way}

Test of Homogeneity of Variances

Table 4.3.3.5

TSCSM

\begin{tabular}{|c|c|c|c|}
\hline $\begin{array}{c}\text { Levene } \\
\text { Statistic }\end{array}$ & df1 & df2 & Sig. \\
\hline 1.560 & 2 & 98 & .215 \\
\hline
\end{tabular}

\section{ANOVA}

\section{Table 4.3.3.6}

SCS

\begin{tabular}{|c|c|c|c|c|c|}
\hline & $\begin{array}{ll}\text { Sum } & \text { of } \\
\text { Squares } & \end{array}$ & Df & Mean Square & $\mathrm{F}$ & Sig. \\
\hline $\begin{array}{l}\text { Between } \\
\text { Groups }\end{array}$ & 170.148 & 2 & 85.074 & .599 & .552 \\
\hline Within Groups & 13925.966 & 98 & 142.102 & & \\
\hline Total & 14096.114 & 100 & & & \\
\hline
\end{tabular}

\section{Multiple Comparisons}

\section{Table 4.3.3.7}

SCS

\begin{tabular}{|ll|l|l|l|}
\hline (I) Experience & $(\mathrm{J})$ Experience & $\begin{array}{l}\text { Mean Difference } \\
(\mathrm{I}-\mathrm{J})\end{array}$ & Std. Error & Sig. \\
\hline 0 - 5 Years & 5.1 - 10 Years & -2.24075 & 2.92707 & .725 \\
& $\begin{array}{l}\text { More than } 10 \\
\text { Years }\end{array}$ & -2.87509 & 2.80867 & .564 \\
& & & \\
\hline
\end{tabular}




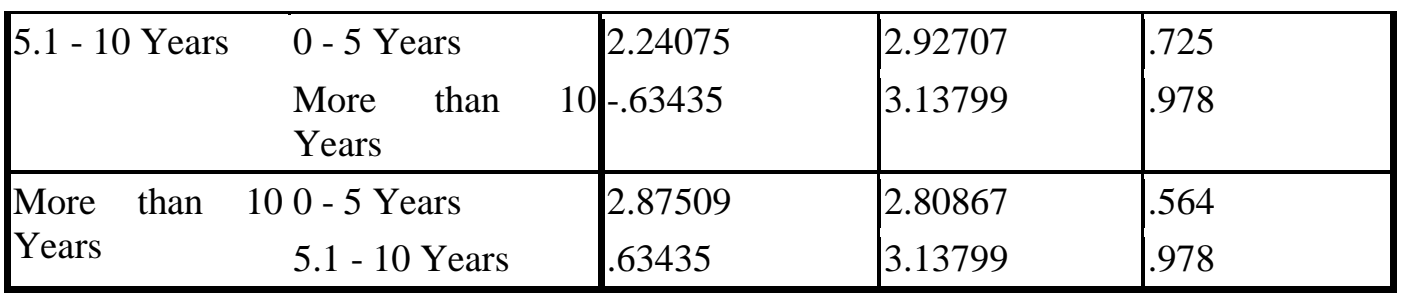

SCS $=$ Stress Coping Styles

A one way between groups is conducted to explore the impact of experience on stress coping style, as measured by life orientation test (LOT). Subjects are divided into three groups (group $1-0-5$ years, group $2-5.1-10$ years, group 3 - more than 10 years). Here the significant value .215 it is greater than .05 .

There is a no positive and significant relationship between experience and stress coping styles.

From the above result, it can be concluded that the hypothesis $\mathbf{H 3 c}$ is not accepted.

\section{Findings of the study}

Findings of the study are based on the result of the hypothesis tested in the present study. The results are as follows:

H1. Doctors of few selected hospitals have high level of Emotional Intelligence.

The hypothesis was supported as the level of the emotional intelligence among doctors was above the scale mean.

H2. Doctors of few selected hospitals have high level of Stress Coping Styles.

The hypothesis was supported as the level of the stress coping style among doctors was above the scale mean.

H3. It is expected that doctor's high emotional intelligence would be more effective to manage stress.

The hypothesis was supported as that they are not highly correlated but they are moderately correlated with each other. If doctors are highly emotional intelligent then they can easily manage their stress.

H4. There is a positive and significant relationship between gender and stress coping styles.

The hypothesis was supported that magnitude of the difference in the mean value is not very large. There is positive and significant relationship between gender and stress coping style.

H5.There is a positive and significant relationship between marital status and stress coping styles. 
The hypothesis was supported that significant value .071 it is greater than .05 . And there is a no positive and significant relationship between marital status and stress coping styles.

H6. There is a positive and significant relationship between experience and stress coping styles.

The hypothesis was supported that the significant value .215 it is greater than .05 . And there is a no positive and significant relationship between experience and stress coping styles.

\section{Recommendations}

In the light of the suggestions given by the doctor's of the selected hospitals and the related review of literature, the following recommendations have been outlined for reviewing and revamping the $\mathrm{HR}$ practices and initiating training on emotional intelligent. Moreover focus should be on hiring employees having high emotional intelligence level. The numerous studies and research on emotional intelligent show that emotional intelligent can be enhanced by learning and behavior modification at any age.

- It is evident from the findings that all the doctors are somehow low on the emotional competencies of impulse control adaptability to change and assertiveness. Thus it is recommended on the basis of the findings and the suggestions given by the doctors in their interviews that the hospitals require to give them assertiveness training and teach them how to delay gratification of short term objectives for long - term gains.

- With regard to gender difference, the management feels that both male and female doctors need to learn the ability to be aware of their feeling, be assertive, independent and confident and develop the ability to adapt to change with ease and be empathetic towards others. This would require introducing various personality development programmes for doctors.

- The hospitals should concentrate on adopting women friendly strategies, as the women are under pressure to strike balance between work and family life. The hospital should provide frequent and timely mentoring and counseling to reduce their stress level along with other facilities like day care for children, family get together etc

- The hospital should try to take down the causes of excessive stress, which are visible through doctors' frustration, absenteeism, tardiness and short temperedness. They should introduce stress busting strategies like yoga, meditation and fitness programmers to enhance the doctors' effectiveness.

- The strenuous working schedules is another major cause of stress for the doctors which can be taken care of by introducing flexi timing, giving them empowerment, responsibility, more accountability, changing assignments, more autonomy and of course participation in decision making would go a long way in soliciting doctors commitment for the hospitals.

- The hospitals should provide playfully productive atmosphere and by generating energy, enthusiasm, creativity amongst its doctors they will work with more devotion and dedication. 


\section{REFERENCES}

Agha Mohammad Hasani P, Mokhtaree M.R, Sayadi A.R, Nazer M, Mosavi S.A, (2012) Study of Emotional Intelligence and Marital Satisfaction in Academic Members of Rafsanjan University of Medical Sciences. Volume 2(2), journal of psychology \& psychotherapy.

BülentGunduz, (2013). Emotional intelligence, cognitive flexibility and psychological symptoms in pre-service teachers. Volume 8(13), pg. 1048-1056.

Cameron Montgomery, Regina Melchor-Beaupré (2004) Stress and Social Problem Solving: Another Wonderful Symbiosis. Volume 1, pg. 87-111. Journal of cognitive education and psychology.

Dr. Sateesh C.P., Dr. Santhosh Kumar R., Dr. Pushpalatha G (2010). Relationship between stress and periodontal disease. Volume 1(1), pg. 54-61, Journal of Dental Sciences and Research.

Estelle, Brink (2009) the relationship between occupational stress, emotional intelligence and coping strategies in air traffic controllers. Volume 3.

GoswamiKakali, Dr. Talukdarrita rani, (2013) Relation between Emotional Intelligence and Job stress among engineer's at Managerial level at Public sector organization. Volume 7(3), journal of humanities and social science.

Gmitrowicz. A., Szczepaniak. A., Jablokowska-Gorecka. K. (2012) the evaluation of the stress coping style and emotional intelligence in psychiatrically treated adolescent patient with deliberate self harm in relation to chosen clinical features. Volume 46, pg. 227-240.

Gail Kinman, Louise Grant, (2010). Emotional intelligence, reflective abilities and wellbeing in social workers and related skills in predicting wellbeing and performance in social work practice. Volume 45, Pg. 1-18.

Hashemi Mohammad Reza (2011) Emotional Intelligence and Self-Efficacy: A Case of Iranian EFL University Students. Volume 3(1), international journal of linguistics.

Hana Chýlová, LudmilaNatovová (2012). Stress coping strategies at university students. Volume 4(1)Pg. 135-158, Journal on Efficiency and Responsibility in Education and Science.

Hayward Brett Anthony, (2005). Relationship between employee performance, leadership and emotional intelligence in a South African parastatalorganisation. Volume 8.

JenniferW. Miller-TaitSpriddle, (2004) Source of stress, stress reactions and coping strategies used by elite female golfers. Volume 7.

JafariEsmaeil (2012). The investigation of relationship between emotional intelligence and coping skills: case study of Tehran university students. Volume 2(7), pg. 6415-6419, journal of basic application science research. 
Keesha L. Karriem (2010). The relationship between stress and emotional intelligence among direct-care workers. Volume 5(1).

Kim Hyun Jeong, Agrusa Jerome (2010) Emotional intelligence and coping style among hospitals industry employees. Volume 8.

Kumar Sunil, Rooprai K. Y., (2009). Role of Emotional Intelligence in Managing Stress and Anxiety at workplace. Volume 16(1).

Mo1"ra Mikolajczak1, K. V. Petrides, Jane Hurry (2009). Adolescents choosing self-harm as an emotion regulation strategy: The protective role of trait emotional intelligence. Volume 48, pg 181-193. British Journal of Clinical Psychology.

MollaeiEinollah, Asayesh Hamid, QorbaniMostafa, Sabzi Zahra (2012). The relationship between emotional intelligence and coping strategies of golestan medical science university students. Volume 17, pg. 127-133.

Noorbakhsh, S.N., Besharat , Mohammad. Ali, Zarei, Jamileh (2010). Emotional intelligence and coping styles with stress. Volume 5, pg. 818-822.

Natalie L. Shipley, Mary Jo Jackson, Sharon Larisa Segrest (2012). The effects of emotional intelligence, age, work experience, and academic performance, Volume 4 (6) Research in Higher Education Journal.

NayakJayshree (2008) Factors influencing stress and coping strategies among the degree college teachers of Dharward City, Karnataka. Volume 5.

Nel, J.A., (2005) Job characteristic, emotional intelligence and wellness in a nursing environment. Volume 8.

RamesarSaras, Koortzen Pieter, Oosthuizen Rudolf M., (2009). The relationship between emotional intelligence and stress management. Volume 35, SA journal of industrial psychology.

Rahim Saddam Hussain (2010). Emotional intelligence and stress: An analytical study of Pakistan banks. Volume 1, International journal of trade.

Richard D.; Costa Jr., Paul T.; Schulze, Ralf (2006). Emotional intelligence, personality, and task-induced stress. Volume 12(2), pg. 96-107, Journal of Experimental Psychology.

SahinNesrinHisli, Guler Murat, Basim H. Nejat (2009) the relationship between cognitive intelligence, emotional intelligence, coping and stress symptoms in the context of type A personality pattern. Volume 14 (1)Turkish journal of psychiatry.

Samuel, O. Salami, (2010) Emotional intelligence, self-efficacy, Pshychological wellbeing and students attitudes: implications for quality education. Volume 2(3), pg. 247-257, European Journal of Educational Studies

Soltanishal Reza, Sharbaf, H.A., KarshkiHossein (2013). The role of type D personality and emotional intelligence with mediating ofperceived stress and coping styles in the quality of life of coronary heart disease patients. Volume 17(7), pg. 449-459. Journal of Kermanshah University of Medical Sciences. 
Ugoji, N. (2010). Perceived emotional intelligence and stress management among undergraduate students. Volume 20.

VaeziShahin, Fallah Nasser (2012). Sense of humor and emotional intelligence as predictors of stress among EFL teachers. Volume 3, pg. 584-591. 